\title{
Towards Increasing the Productivity of Lignocellulosic Bioethanol: Rational Strategies Fueled by Modeling
}

\author{
Hyun-Seob Song, John A. Morgan and Doraiswami Ramkrishna \\ School of Chemical Engineering, Purdue University, West Lafayette, IN
}

USA

\section{Introduction}

Bioethanol is not only currently the most widely used biofuel, but also potentially the most promising alternative to fossil fuels. The majority of bioethanol in today's use is made from sucrose-containing (e.g., sugarcane, sugar beet, and sweet sorghum) or starch-based feedstocks (e.g., corn, wheat, rice, barley, and potatoes). The excessive production of such crop-based (first generation) bioethanol, however, imposes an adverse effect on global food supply. A sustainable alternative feedstock which can be used for non-crop (second generation) bioethanol is lignocellulosic biomass such as rice straw (Binod et al., 2010), wheat straw (Talebnia et al., 2010), corn stover (Kadam \& McMillan, 2003), switchgrass (Keshwani \& Cheng, 2009), sugarcane bagasse (Cardona et al., 2010), and various other agriculture and forest residues.

Lignocellulose primarily consists of cellulose, hemicellulose and lignin. Cellulose is a homopolymer of glucose, while hemicellulose is a heteropolymer of pentoses (i.e., xylose and arabinose) and hexoses (i.e., glucose, mannose, and galactose) sugars. Lignin is a rich source of aromatic carbon compounds but extremely recalcitrant. Lignocellulose is decomposed via pretreatment and hydrolysis into a spectrum of sugars in which glucose and xylose are the first and second most dominant. These cellulosic sugars are finally converted to bioethanol by fermentation. The lignocellulosic bioethanol has not yet been produced on a commercial scale due to lack of cost-effectiveness. For ensuring its economical viability, comprehensive efforts are required to reduce cost (and maximize the profit) throughout the entire process from biomass to bioethanol.

In the current discussion, we limit ourselves to the fermentation step only and examine various issues with increasing bioethanol productivity. Cost-benefit analysis of the fermentation process shows that the processing cost is more dominant (two-thirds of the total cost) than the feed cost (Lange, 2007; Wingren et al., 2003). It is thus important to improve the processing efficiency, not just the sugar conversion alone. In this regard, increasing the productivity should be a preferred target over increasing the yield, not only in the reactor optimization, but also in strain improvement.

The yeast Saccharomyces cerevisiae has typically been used for the production of crop-based bioethanol. This wild-type strain is, however, not suitable for converting cellulosic sugars as it can efficiently ferment glucose but hardly xylose. Considerable effort has been made to 
endow S. cerevisiae with the ability to utilize xylose (Hahn-Hagerdal et al., 2007). Basic approaches to this end are to "push" and "pull" xylose into the central metabolism of $S$. cerevisiae. Push strategies introduce the transport and initial metabolic routes of xylose by expressing exogenous (i.e., foreign) genes. In pull strategies, reactions in the central metabolism are selectively overexpressed. Introduction of foreign plasmids imposes a "metabolic burden" or "metabolic load" on the host cell by consuming a significant amount of internal resources, hurting the normal metabolic functioning of the host cell (Glick, 1995). The most common observation is the decrease of cell growth rate (Bentley et al., 1990; Ricci \& Hernandez, 2000). It is often (while not always) that as the product yield is increased, the production rate is reciprocally low (Chu \& Lee, 2007).

Most of the recombinant yeast strains currently available show a sequential pattern in their consumption of mixed sugars (i.e., glucose and xylose). They preferably consume glucose with xylose on standby as denoted by the vertical line in Fig. 1.1(a). Then, simultaneous consumption take places along the tilted line only when the preferred substrate is depleted to a very low level (say, one tenth or one fifth of xylose level). Obviously, the productivity can be increased if simultaneous consumption occurs earlier (i.e. at higher concentrations of glucose). To achieve this, two different strategies can be considered. First, we may develop a more efficient fermenting organism through further pathway modifications of existing recombinant yeast. The goal of this attempt at the genetic level corresponds to making the slope of the tilted line steeper (Fig. 1.1(b)). Alternatively, we may design a more efficient fermentation process through optimization of operating conditions or reconfiguration of reactors. For example, if we change initial sugar composition in batch culture by increasing relative portion of xylose in the culture medium, this also leads to earlier start of the simultaneous consumption (Fig. 1.1(c)).

(a)

a)

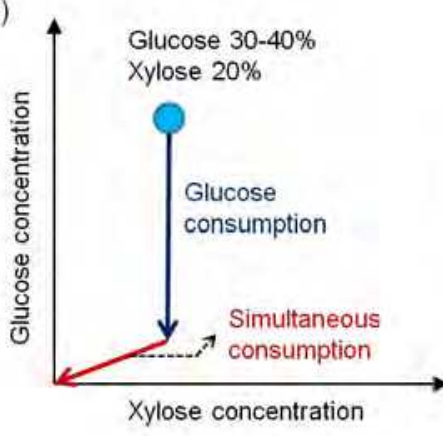

(b)

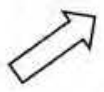

(c)
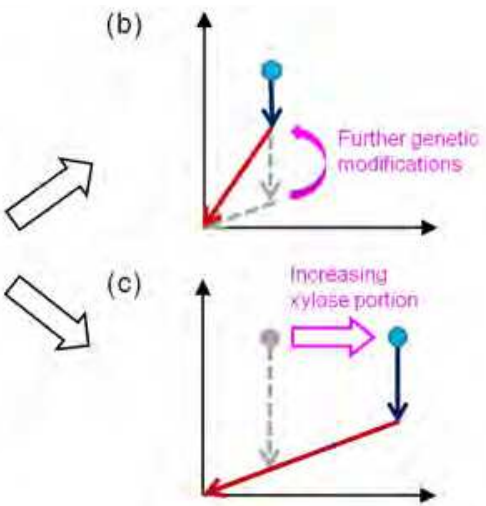

Fig. 1.1. (a) Sequential consumption of mixed sugars by existing recombinant yeast. Two possible ways to promote the simultaneous consumption: (b) metabolic pathway modification of fermenting organisms and (c) adjustment of sugar composition in the culture medium. Adapted from Song and Ramkrishna (2010) with minor modification.

In this chapter, we present model-based strategies for increasing the bioethanol productivity both at the genetic and reactor levels. Metabolic models help not only reduce trial and error, but also discover fresh strategies (Bailey, 1998). In view of the issues discussed above, there are two essential aspects of metabolic models required for the application to reactor and 
metabolic engineering. First, the mathematical models should be able to address productivity as well as yield. Second, it should be possible to account for metabolic burden. While diverse modeling approaches have been suggested as a tool, the cybernetic framework (Ramkrishna, 1983) is unique in this regard (Maertens \& Vanrolleghem, 2010).

The cybernetic modeling approach describes cellular metabolism from the viewpoint that a microorganism is an optimal strategist making frugal use of limited internal resources to maximize its survival (Ramkrishna, 1983). Metabolic regulation of enzyme synthesis and their activities is made as the outcome of such optimal allocation of resources. This unique feature of accounting for metabolic regulation endows cybernetic models with the capability to accurately predict peculiar metabolic behaviors such as sequential or simultaneous consumption of multiple substrates. Further, in view of the constraint placed on resources, the cybernetic model provides a mechanism to account for metabolic burden imposed on the organism as a result of genetic changes.

After a brief sketch of the model structure (Section 2), we will see how metabolic models are used to establish rational strategies for increasing the productivity. In Section 3, basic guidelines for genetic modification of fermenting organisms are provided by identifying the potential target pathway and reactions. Diverse reactor-level strategies are also discussed in Section 4 .

\section{Metabolic model}

The hybrid cybernetic approach (Kim et al., 2008; Song et al., 2009; Song \& Ramkrishna, 2009) is used for modeling of recombinant yeast consuming glucose and xylose. The hybrid cybernetic model (HCM) incorporates the concept of elementary modes (EMs) (Schuster et al., 2000) into the cybernetic framework. EM is a metabolic pathway (or subnetwork) composed of a minimal set of reactions supporting a steady state operation of metabolism. Any feasible metabolic state can be represented by nonnegative combinations of EMs. HCM views EMs as cell's metabolic options, the choice of which is optimally modulated under dynamic environmental conditions such that a prescribed metabolic objective (such as the total carbon uptake flux) is maximized.

\subsection{Basic structure}

A hybrid cybernetic model can be given in a general form as follows:

$$
\begin{aligned}
& \frac{d \mathbf{x}}{d t}=\mathbf{S}_{\mathbf{x}} \mathbf{Z r}_{\mathbf{M}^{c}}+\frac{F_{I N}}{V}\left(\mathbf{x}_{\text {IN }}-\mathbf{x}\right) \\
& \frac{d V}{d t}=F_{I N}-F_{\text {OUT }}
\end{aligned}
$$

where $\mathbf{x}$ is the vector of $n_{x}$ concentrations of extracellular components in the reactor (such as substrates, products and biomass), $\mathbf{S}_{\mathbf{x}}$ is the $\left(n_{x} \times n_{r}\right)$ stoichiometric matrix, and $\mathbf{Z}$ is the $\left(n_{r} \times n_{z}\right)$ EM matrix, $\mathbf{r}_{\mathrm{M}}$ is the vector of $n_{z}$ fluxes through EMs, $F_{I N}$ and $F_{O U T}$ are volumetric feed rates at the inlet and outlet, $V$ is the culture volume, $\mathbf{x}_{\mathbf{I N}}$ is the vector of $n_{x}$ concentrations of extracellular components in the feed. Eq. (1) can also represent batch operation by setting $F_{I N}=F_{\text {OUT }}=0$ (i.e., $V$ is constant), and fed-batch systems by setting $F_{\text {OUT }}=0$. In chemostat operations, $F_{I N}=F_{O U T}=F$, and $F / V$ is often given as dilution rate $D$. With $\mathbf{Z}$ normalized with respect to a reference substrate, $\mathbf{r}_{M}$ implies uptake fluxes through EMs. Fluxes through EMs are given as below: 


$$
r_{M, j}=v_{M, j}\left(e_{M, j} / e_{M, j}^{\max }\right) r_{M, j}^{k i n}
$$

where the subscript $j$ denotes the index of EM, $v_{M, j}$ is the cybernetic variable controlling enzyme activity, $e_{M, j}$ and $e_{M, j}^{\max }$ are the enzyme level and its maximum value, respectively, and $r_{M, j}^{k i n}$ is the kinetic term. Enzyme level $e_{M, j}$ is obtained from the following dynamic equation, i.e.,

$$
\frac{d e_{M, j}}{d t}=\alpha_{M, j}+u_{M, j} b r_{M E, j}^{k i n}-\beta_{M, j} e_{M, j}-\mu e_{M, j}
$$

where the first and second terms of the right-hand side denote constitutive and inducible rates of enzyme synthesis, and the last two terms represent the decrease of enzyme levels by degradation and dilution, respectively. In the second term of the right-hand side, $u_{M, j}$ is the cybernetic variable regulating the induction of enzyme synthesis, $b$ is the fraction of internal resources (such as DNA, RNA, protein, lipid and other components) involved in the enzyme synthesis process, and $r_{M E, j}^{k i n}$ is the kinetic part of inducible enzyme synthesis rate. In the third and fourth terms, $\beta_{M, j}$ and $\mu$ are the degradation and specific growth rates, respectively.

The cybernetic control variables, $u_{M, j}$ and $v_{M, j}$ are computed from the following the "Matching Law" and the "Proportional Law"(Kompala et al., 1986; Young \& Ramkrishna, 2007), respectively:

$$
u_{M, j}=\frac{p_{j}}{\sum_{k} p_{k}} ; \quad v_{M, j}=\frac{p_{j}}{\max _{k}\left(p_{k}\right)}
$$

where the return-on-investment $p_{j}$ denotes the carbon uptake flux through the $j$ th EM.

The structure of HCMs is illustrated using Fig. 2.1. In this tutorial example, we get three EMs from the network. The uptake flux is split into three individual fluxes thorough EMs, which are catalyzed by enzymes $E_{1}, E_{2}$ and $E_{3}$, respectively. HCMs view that the uptake fluxes are optimally distributed (by the cybernetic variables $\mathbf{u}$ and $\mathbf{v}$ ) among three EMs for maximizing a metabolic objective function (such as the carbon uptake flux or growth rate). The uptake and excretion rates are represented by nonnegative combinations of individual fluxes through EMs.

\subsection{Recombinant yeast strain 1400 (pLNH33)}

Among many recombinant yeast strains currently available, we specifically choose $S$. cerevisiae 1400 (pLNH33) developed by Ho and coworkers (Krishnan et al., 1997). The strain was constructed by transforming the recombinant plasmids with two exogenous genes XYL1 and XYL2 (introduced from xylose-metabolizing Pichia stipitis), and one endogenous gene XKS1 (introduced from S. cerevisiae) into the host strain Saccharomyces yeast 1400 with high ethanol tolerance (Krishnan et al., 1997). The first two genes encode xylose reductase $(\mathrm{XR})$ and xylitol dehydrogenase $(\mathrm{XDH})$, which convert xylose to xylitol, and xylitol to xylulose, respectively, and the last one encodes xylulokinase $(\mathrm{XK})$, which converts xylulose to xylulose-5-phophaste.

The HCM for the recombinant yeast 1400 (pLNH33) is presented below. The model has been previously developed by the authors (Song et al., 2009). The formulation of HCM is 


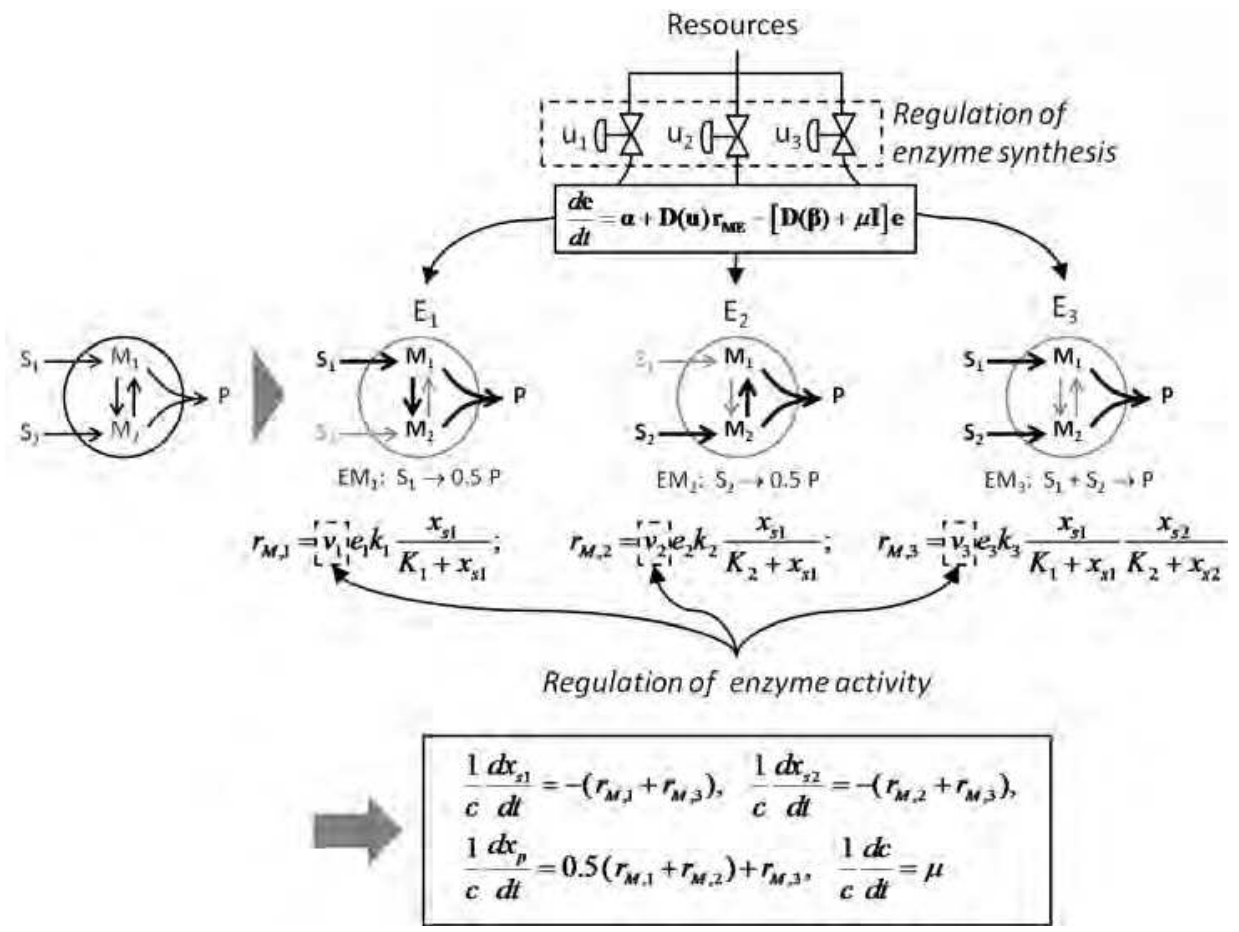

Fig. 2.1. Schematic illustration of the HCM concept. Adapted from from Song et al. (2009).

composed of (i) construction of metabolic network, (ii) computation and selection of EMs, and (iii) parameter identification by model fitting.

\subsection{Construction of network model}

The metabolic network encompasses all the primary reaction routes involved in the anaerobic growth of recombinant yeast such as glycolytic and pentose phosphate pathways, citric acid cycle, and reactions for pyruvate metabolism. In addition, two oxidoreductase reactions from xylose to xylulose catalyzed by the heterologous expression of XR and XDH enzymes are incorporated. Biochemical reactions participating in the metabolism of recombinant yeast are listed up in Table 2.1.

\subsection{EM decomposition and reduction}

Using METATOOL v5.0 (von Kamp \& Schuster, 2006), the network is decomposed into 201 EMs, which are too many to be incorporated in the model. In general, as the network size increases, the number of EMs undergoes combinatorial explosion (Klamt \& Stelling, 2002), leading to overparameterization (which implies an excessive number of parameters relative to the measurements available to determine them). This problem can be avoided using the Metabolic Yield Analysis (MYA) developed by Song and Ramkrishna (2009) by which an original set of EMs is condensed to a much smaller subset. As a result, 201 EMs are reduced to 12 EMs which can be classified into three groups depending on the substrate associated with them (Table 2.2). 


\begin{tabular}{|c|c|c|c|}
\hline \multicolumn{4}{|c|}{ GLYCOLYSIS } \\
\hline 1 & $\mathrm{GLC}+\mathrm{ATP} \rightarrow \mathrm{G} 6 \mathrm{P}+\mathrm{ADP}$ & 6 & $\mathrm{GOL} \rightarrow \mathrm{GOL}_{\mathrm{x}}$ \\
\hline 2 & $\mathrm{G} 6 \mathrm{P} \leftrightarrow \mathrm{F} 6 \mathrm{P}$ & 7 & $\mathrm{GAP}+\mathrm{NAD}+\mathrm{ADP} \leftrightarrow \mathrm{PG} 3+\mathrm{NADH}+\mathrm{ATP}$ \\
\hline 3 & $\mathrm{~F} 6 \mathrm{P}+\mathrm{ATP} \leftrightarrow \mathrm{DHAP}+\mathrm{GAP}+\mathrm{ADP}$ & 8 & $\mathrm{PG} 3 \leftrightarrow \mathrm{PEP}$ \\
\hline 4 & $\mathrm{DHAP} \leftrightarrow \mathrm{GAP}$ & 9 & $\mathrm{PEP}+\mathrm{ADP} \leftrightarrow \mathrm{PYR}+\mathrm{ATP}$ \\
\hline 5 & $\mathrm{DHAP}+\mathrm{NADH} \rightarrow \mathrm{GOL}+\mathrm{NAD}$ & & \\
\hline \multicolumn{4}{|c|}{ PYRUVATE METABOLISM } \\
\hline 10 & $\mathrm{PYR} \rightarrow \mathrm{ACD}+\mathrm{CO}_{2}$ & 14 & $\mathrm{ACT} \rightarrow \mathrm{ACT}_{\mathrm{x}}$ \\
\hline 11 & $\mathrm{ACD}+\mathrm{NADH} \rightarrow \mathrm{ETH}+\mathrm{NAD}$ & 15 & $\mathrm{ACT}+\mathrm{CoA}+2 \mathrm{ATP} \rightarrow \mathrm{AcCoA}+2 \mathrm{ADP}$ \\
\hline 12 & $\mathrm{ACD}+\mathrm{NADH}_{\mathrm{m}} \rightarrow \mathrm{ETH}+\mathrm{NAD}_{\mathrm{m}}$ & 16 & $\mathrm{PYR}+\mathrm{ATP}+\mathrm{CO}_{2} \rightarrow \mathrm{OAA}+\mathrm{ADP}$ \\
\hline 13 & $\mathrm{ACD}+\mathrm{NADP} \rightarrow \mathrm{ACT}+\mathrm{NADPH}$ & & \\
\hline \multicolumn{4}{|c|}{ PENTOSE PHOSPHATE PATHWAY } \\
\hline 17 & $\mathrm{G} 6 \mathrm{P}+2 \mathrm{NADP} \rightarrow \mathrm{Ru} 5 \mathrm{P}+\mathrm{CO}_{2}+2 \mathrm{NADPH}$ & 20 & $\mathrm{R} 5 \mathrm{P}+\mathrm{X} 5 \mathrm{P} \leftrightarrow \mathrm{S} 7 \mathrm{P}+\mathrm{GAP}$ \\
\hline 18 & $\mathrm{Ru} 5 \mathrm{P} \leftrightarrow \mathrm{X} 5 \mathrm{P}$ & 21 & $\mathrm{X} 5 \mathrm{P}+\mathrm{E} 4 \mathrm{P} \leftrightarrow \mathrm{F} 6 \mathrm{P}+\mathrm{GAP}$ \\
\hline 19 & $\mathrm{Ru} 5 \mathrm{P} \leftrightarrow \mathrm{R} 5 \mathrm{P}$ & 22 & $\mathrm{~S} 7 \mathrm{P}+\mathrm{GAP} \leftrightarrow \mathrm{F} 6 \mathrm{P}+\mathrm{E} 4 \mathrm{P}$ \\
\hline \multicolumn{4}{|c|}{ CITRIC ACID CYCLE } \\
\hline 23 & $\mathrm{PYR}+\mathrm{NAD}_{\mathrm{m}}+\mathrm{CoA}_{\mathrm{m}} \rightarrow \mathrm{AcCoA}_{\mathrm{m}}+\mathrm{CO}_{2}+\mathrm{NADH}_{\mathrm{m}}$ & 27 & $\mathrm{ICT}+\mathrm{NADP}_{\mathrm{m}} \rightarrow \mathrm{AKG}+\mathrm{CO}_{2}+\mathrm{NADPH}_{\mathrm{m}}$ \\
\hline 24 & $\mathrm{OAA}+\mathrm{NAD}+\mathrm{NADH} \leftrightarrow \mathrm{OAA}_{\mathrm{m}}+\mathrm{NADH}_{\mathrm{m}}+\mathrm{NAD}$ & 28 & $\mathrm{AKG}+\mathrm{NAD} \mathrm{m}+\mathrm{ADP} \rightarrow \mathrm{SUC}+\mathrm{ATP}+\mathrm{CO}_{2}+\mathrm{NADH}_{\mathrm{m}}$ \\
\hline 25 & $\mathrm{OAA}_{\mathrm{m}}+\mathrm{AcCoA}_{m} \rightarrow \mathrm{ICT}+\mathrm{CoA}_{\mathrm{m}}$ & 29 & $\mathrm{SUC}+0.5 \mathrm{NAD}_{\mathrm{m}} \leftrightarrow \mathrm{MAL}+0.5 \mathrm{NADH}_{\mathrm{m}}$ \\
\hline 26 & $\mathrm{ICT}+\mathrm{NAD}_{\mathrm{m}} \rightarrow \mathrm{AKG}+\mathrm{CO}_{2}+\mathrm{NADH}_{\mathrm{m}}$ & 30 & $\mathrm{MAL}+\mathrm{NAD}_{\mathrm{m}} \leftrightarrow \mathrm{OAA}_{\mathrm{m}}+\mathrm{NADH}_{\mathrm{m}}$ \\
\hline \multicolumn{4}{|c|}{ XYLOSE METABOLISM } \\
\hline 31 & $\mathrm{XYL}+\mathrm{NADH} \rightarrow \mathrm{XOL}+\mathrm{NAD}$ & 34 & $\mathrm{XOL}+\mathrm{NAD} \rightarrow \mathrm{XUL}+\mathrm{NADH}$ \\
\hline 32 & $\mathrm{XYL}+\mathrm{NADPH} \rightarrow \mathrm{XOL}+\mathrm{NADP}$ & 35 & $\mathrm{XUL}+\mathrm{ATP} \rightarrow \mathrm{X} 5 \mathrm{P}+\mathrm{ADP}$ \\
\hline 33 & $\mathrm{XOL} \rightarrow \mathrm{XOL}_{\mathrm{x}}$ & & \\
\hline \multicolumn{4}{|c|}{ BIOMASS FORMATION } \\
\hline 36 & \multicolumn{3}{|c|}{$\begin{array}{l}\text { 1.04AKG + 0.57E4P + 0.11GOL + 2.39G6P + 1.07OAA + 0.99PEP + 0.57PG3 + 1.15PYR + 0.74R5P + 2.36AcCoA } \\
+0.31 \mathrm{AcCo} \mathrm{A}_{\mathrm{m}}+2.68 \mathrm{NAD}+0.53 \mathrm{NAD}_{\mathrm{m}}+11.55 \mathrm{NADPH}^{\prime}+1.51 \mathrm{NADPH} \mathrm{H}_{\mathrm{m}}+30.48 \mathrm{ATP}+0.43 \mathrm{CO}_{2} \rightarrow \text { " } 1 \mathrm{gIOM}^{\prime \prime} \\
+2.36 \mathrm{CoA}+0.31 \mathrm{Co} \mathrm{A}_{\mathrm{m}}+2.68 \mathrm{NADH}+0.53 \mathrm{NADH}_{\mathrm{m}}+11.55 \mathrm{NADP}+1.51 \mathrm{NADP}_{\mathrm{m}}+30.48 \mathrm{ADP}\end{array}$} \\
\hline \multicolumn{4}{|c|}{ OTHERS } \\
\hline 37 & $\mathrm{ATP} \rightarrow \mathrm{ADP}+\mathrm{MAINT}$ & 38 & $\mathrm{NADH} \rightarrow \mathrm{NAD}$ \\
\hline
\end{tabular}

Table 2.1. List of biochemical reactions included in the metabolic network model of recombinant yeast 1400 (pLNH33). Adapted from Song and Ramkrishna (2009).

\begin{tabular}{|c|c|c|}
\hline Substrate & EM & Net reaction \\
\hline \multirow{3}{*}{ Glucose } & 1 & $\mathrm{GLC} \rightarrow 2 \mathrm{CO} 2+2 \mathrm{ETH}+2 \mathrm{MAINT}$ \\
\hline & 2 & $25.31 \mathrm{GLC} \rightarrow \mathrm{BIOM}+41.43 \mathrm{CO} 2+33.21 \mathrm{ETH}$ \\
\hline & 3 & $40.41 \mathrm{GLC} \rightarrow \mathrm{BIOM}+56.52 \mathrm{CO} 2+48.31 \mathrm{ETH}+15.10 \mathrm{GOLx}$ \\
\hline \multirow{4}{*}{ Xylose } & 4 & $\mathrm{XYL} \rightarrow 1.833 \mathrm{CO} 2+1.583 \mathrm{ETH}+1.583 \mathrm{MAINT}$ \\
\hline & 5 & $2 \mathrm{XYL} \rightarrow 2 \mathrm{CO} 2+1.5 \mathrm{ETH}+1.5 \mathrm{MAINT}+\mathrm{XOLx}$ \\
\hline & 6 & $31.97 \mathrm{XYL} \rightarrow \mathrm{BIOM}+49.42 \mathrm{CO} 2+33.21 \mathrm{ETH}$ \\
\hline & 7 & $138.5 \mathrm{XYL} \rightarrow \mathrm{BIOM}+160.4 \mathrm{CO} 2+117.6 \mathrm{ETH}+84.37 \mathrm{GOLx}$ \\
\hline \multirow{5}{*}{ Mixture } & 8 & $\mathrm{GLC}+4 \mathrm{XYL} \rightarrow 2 \mathrm{ACTx}+2 \mathrm{CO} 2+2 \mathrm{MAINT}+4 \mathrm{XOLx}$ \\
\hline & 9 & $\mathrm{GLC}+4 \mathrm{XYL} \rightarrow 9.333 \mathrm{CO} 2+8.333 \mathrm{ETH}+8.333 \mathrm{MAINT}$ \\
\hline & 10 & 2.39 GLC + 25.99 XYL $\rightarrow 22.19 \mathrm{ACT} x+\mathrm{BIOM}+37.82 \mathrm{CO} 2+9.037 \mathrm{ETH}$ \\
\hline & 11 & $5.333 \mathrm{GLC}+2 \mathrm{XYL} \rightarrow \mathrm{ACTx}+8.5 \mathrm{CO} 2+4.5 \mathrm{ETH}+7.5 \mathrm{GOLx}$ \\
\hline & 12 & $\begin{array}{l}81.62 \mathrm{GLC}+\mathrm{XYL} \rightarrow 12.03 \mathrm{ACTx}+1.754 \mathrm{BIOM}+105.9 \mathrm{CO} 2+85.25 \\
\mathrm{ETH}+39.01 \mathrm{GOLx}\end{array}$ \\
\hline
\end{tabular}

Table 2.2. EMs represented in terms of extracellular metabolites. Acronyms for metabolites: $\mathrm{ACT} x=$ acetate, $\mathrm{BIOM}=$ biomass, $\mathrm{CO} 2=$ carbon dioxide, $\mathrm{ETH}=$ ethanol, $\mathrm{GLC}=$ glucose, $\mathrm{GOL}=$ glycerol, $\mathrm{MAINT}=$ Dissipated ATP for maintenance, $\mathrm{XOLx}=\mathrm{xylitol}, \mathrm{XYL}=\mathrm{xylose}$. 


\subsection{Model fit to experimental data}

The model was compared with four different sets of anaerobic growth data on single and mixed sugars (Fig. 2.2). As a measure for the quality of model fit, coefficient of determination (also referred to as $\mathrm{R}^{2}$ ) is presented for each component of Figs. 2.2(a) to (d) (Table 2.3). $\mathrm{R}^{2}$ is defined as follows:

$$
R^{2} \equiv 1-\frac{S S_{e r r}}{S S_{\text {tot }}} ; \quad S S_{\text {err }}=\sum_{i}\left(y_{i, \exp }-y_{i, \text { model }}\right)^{2}, \quad S S_{t o t}=\sum_{i}\left(y_{i, \exp }-\bar{y}_{\exp }\right)^{2},
$$

where $y_{i, \exp }, y_{i, \text { model }}$, and $\bar{y}_{\exp }$ denote experimental data, their associated modeled value, and the mean of the observed data, respectively. $\mathrm{R}^{2}$ values are very high (i.e., over 0.9 ) for major components (such as glucose, xylose, biomass and ethanol). $\mathrm{R}^{2}$ values of minor components (such as glycerol and xylitol) are relatively low which is possibly due to the error introduced in data reading from literature graphs. Average $\mathrm{R}^{2}$ values are over 0.8 in all cases.
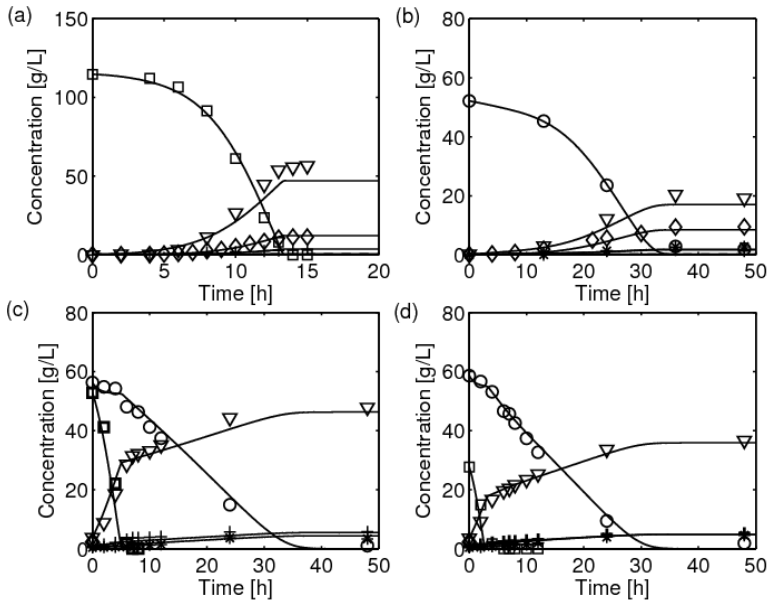

Fig. 2.2. Comparison of model simulations with experimental data. Substrates: (a) glucose only, (b) xylose only, (c) and (d) mixed sugars. Symbols: $\square$ glucose, $\bigcirc$ xylose, $\nabla$ ethanol, $\diamond$ cell dry weight, + glycerol, * xylitol, - simulations.

\begin{tabular}{lcccc}
\hline & \multicolumn{4}{c}{ Fig. 2.2 } \\
\cline { 2 - 5 } & (a) & (b) & (c) & (d) \\
\hline Glucose & 0.997 & - & 0.972 & 0.982 \\
Xylose & - & 0.974 & 0.985 & 0.990 \\
Cell dry weight & 0.988 & 0.929 & - & - \\
Ethanol & 0.936 & 0.926 & 0.956 & 0.957 \\
Glycerol & 0.788 & 0.857 & 0.501 & 0.480 \\
Xylitol & - & 0.828 & 0.838 & 0.729 \\
\hline Average & 0.927 & 0.903 & 0.850 & 0.828 \\
\hline
\end{tabular}

Table 2.3. Coefficient of determination (or $\mathrm{R}^{2}$ ) for individual components of Figs. 2.2(a) to (d). 


\section{Strategies for metabolic pathway modification}

Comprehensive in silico analysis is carried out to establish rational guidelines for further genetic modification of recombinant yeast. The basic strategy is to identify the effective target mode for the genetic change. To this end, we examine the effect of overexpressing enzymes (catalyzing the throughput flux of EMs) on the ethanol productivity $\left(P_{E T H}\right)$ which is computed as follows:

$$
P_{E T H}=\left[x_{E T H}\left(t_{f}\right)-x_{E T H}(0)\right] / t_{f}
$$

where $x_{E T H}$ is the (molar or mass) concentration of ethanol, and $t_{f}$ is the batch fermentation time.

For realistic simulations, incorporation of metabolic burden is critical. Metabolic burden is ascribed to the lower availability of internal resources for host cells because the same resources are competitively used by plasmids for their replication and more importantly, the synthesis of exogenous proteins. While several empirical correlations are available to consider the change of growth rate with the plasmid content (e.g., Lee et al., 1985; Satyagal \& Agrawal, 1989), cybernetic models are able to directly take into account of the reduction of internal resources $(b)$, for example, as follows:

$$
b=\frac{b_{0}}{1+\phi}
$$

where $\phi$ is the parameter depending on the overexpressed level of heterologous proteins as well as the plasmid copy number, and $b_{0}$ denotes the fraction of internal resources when no genetic modification is made (i.e., $\phi=0$ ). We simulate enzyme overexpression by increasing the constitutive enzyme synthesis rate ( $\alpha_{M, j}$ 's) in Eq. (3) and relate $\phi$ to the ratio of "the total incremental of $\alpha_{M, j}$ 's due to plasmids" to "the summation of inducible enzyme synthesis rates."

\subsection{Identification of target pathway}

Sensitivity analysis reveals the dependence of the ethanol productivity on the overexpression of enzymes catalyzing EM fluxes. The sensitivity of the ethanol productivity is calculated as follows:

$$
\text { Sensitivity of } P_{E T H}=\frac{\alpha_{M, j}}{P_{E T H}} \frac{d P_{E T H}}{d \alpha_{M, j}}, \quad j \in\{1,2, \ldots, 12\}
$$

The sensitivity plot (Fig. 3.1(a)) shows that all xylose-consuming EMs (EM4 to EM7) are effective in increasing the ethanol productivity but the highest sensitivity is found among glucose-consuming modes (i.e., EM2). Both can contribute to increasing the productivity but in different ways. The former (i.e., amplifying fluxes of EM4 to EM7) promotes the simultaneous consumption of mixed sugars as illustrated in Fig. 1.1(b). On the other hand, the latter (i.e., amplifying EM2 flux) effectively increases the biomass formation as the growth rate of EM2 is the highest among others.

It should be noted that information provided from the sensitivity analysis is local because it shows only the change of productivity with respect to the "infinitesimal" change of enzyme 
expression level. It is more important to know how the productivity will change with respect to the "appreciable" change of enzyme levels. This information on nonlinear cellular behaviors can be acquired from dynamic simulations. The results are shown in Fig. 3.1(b) where mixed-sugar-consuming modes (EM8 to EM12) are excluded due to their negligible level of activation (Song et al., 2009). From this investigation, EM6 (red line) is chosen as the "best" mode, while EM2 is the second.

Non-monotonic profiles are observed in Fig. 3.1(b). For example, as the overexpression level of mode 5 increases, the productivity goes up initially but comes down afterwards. This may be seen as the outcome of competition between amplification of throughput flux of EM4 (i.e., benefit) and metabolic burden (i.e., cost).
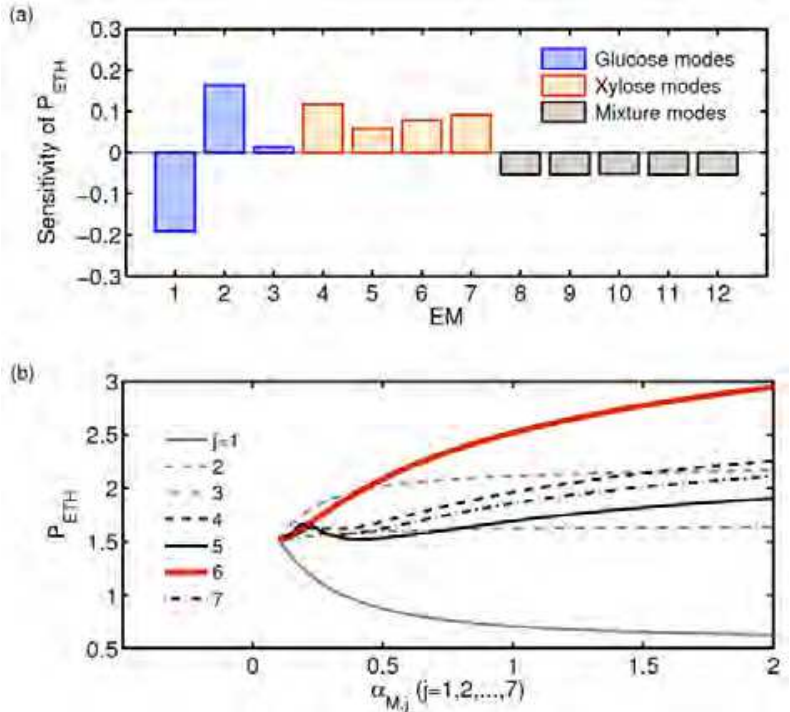

Fig. 3.1. The effect of enzyme overexpression on the ethanol productivity: (a) sensitivity of the productivity, (b) change of productivity subject to appreciable change of enzyme level.

\subsection{Effect of amplifying the flux of the target pathway}

The effect of amplifying EM6 flux on ethanol productivity is more clearly presented in batch fermentation profiles (Fig. 3.2).

Obviously, overexpression of enzymes has a limit due to the finite internal resources and other reasons. Although it is difficult to estimate the upper limit to overexpression level, we constrain the constitutive synthesis rates of enzymes to be less than a certain threshold, i.e., the total increase of $\alpha_{M, j}$ 's is less than or equal to 0.4 .

Fig. 3.2 shows that xylose consumption rate is accelerated, while glucose consumption rate is reduced. The decrease of glucose consumption rate can be attributed to a combined effect of metabolic burden and cellular regulation. Consequently, simultaneous consumption of glucose and xylose is facilitated, leading to the substantial increase of ethanol productivity from 1.5 to $2.07 \mathrm{~g} / \mathrm{L} / \mathrm{h}$ (i.e., increase of volumetric productivity by $38 \%$ ), while the ethanol yield is slightly decreased from 0.402 to 0.392 . The total conversion of mixed sugars is fixed to 0.99 in this calculation. 
(a)

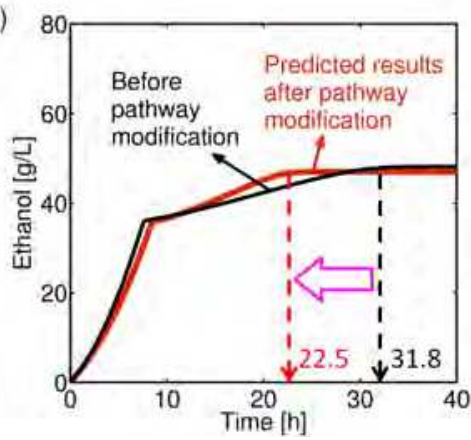

(b)

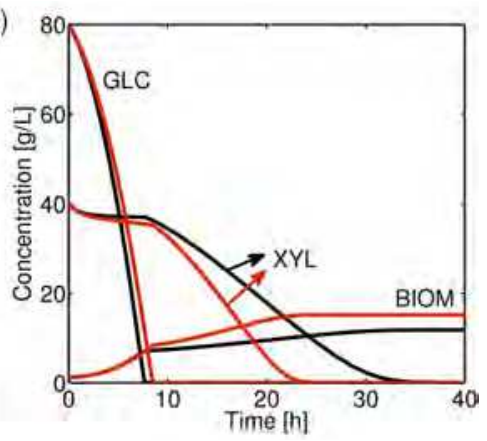

Fig. 3.2. Dynamic fermentation curves in a batch reactor before (black lines) and after (red lines) overexpressing the target mode (EM6). (a) Ethanol, (b) glucose (GLC), xylose (XYL) and biomass (BIOM).

\subsection{Implications of amplifying EM6 flux}

Comparison of the flux distributions between before $(\mathbf{r})$ and after $\left(\mathbf{r}^{\prime}\right)$ pathway modification suggests an approach to redirect flux distribution for increasing ethanol productivity. Fig. 3.3(a) shows $\mathbf{r}$ and $\mathbf{r}^{\prime}$ at a specific instant when cell density is $3 \mathrm{~g} / \mathrm{L}$. Metabolic shift caused by the genetic change is also presented by displaying the difference between $\mathbf{r}$ and $\mathbf{r}^{\prime}$ (Fig. 3.3(b)). Then, amplification of the mode throughput flux could be translated as amplification of a set of reactions with positive values of $\mathbf{r}^{\prime}-\mathbf{r}$ which are highlighted in colors in Figs. 3.3(a) and (b). From this analysis, we obtain several interesting findings as follows:

i. First of all, it is observed that none of the reactions in the glycolytic pathway are amplified. It implies that amplification of the glycolytic enzymes may not be a key to increasing ethanol productivity. This is consistent with experimental findings reported in the literature. Overproduction of different glycolytic enzymes of S. cerevisiae showed no effect on the rate of ethanol formation (Schaaff et al., 1989). It is because flux control is not inside the glycolytic pathway. Understandably, past efforts for increasing the glycolytic flux by overproduction of glycolytic enzymes have been often unsuccessful (Koebmann et al., 2002). In the in silico analysis, flux control is found elsewhere (highlighted in color) which includes xylose utilization pathway, and pentose phosphate (PP) pathway.

ii. While recombinant strain 1400 (pLNH33) efficiently utilizes xylose through the pathway constructed by overexpressing exogenous genes (XR and $\mathrm{XDH})$, as well as endogenous gene $(\mathrm{XK})$, simulation shows that the increase of ethanol productivity requires further overexpression of not only xylose transport reactions (i.e., R31 and R32), but also xylitol conversion to X5P (i.e., R34 and R35).

iii. In addition, it is shown that four reactions in the PP pathway (R19 to R22), i.e., transaldolase (TAL1), transketolase (TKL1), ribulose-5-phosphate 4-epimerase (RPE1) and ribulokinase (RKI1), are possible targets for overexpression. The finding by Johansson \& Hahn-Hagerdal (2002) that overexpression of all four genes resulted in better ethanol production than the overexpression of each gene individually is also consistent with the simulation result.

iv. Another interesting aspect that emerges from the model is as follows. Jeppsson et al. (2002) observed that deletion of ZWF1 (i.e., R17), coding for glucose-6-phosphate 
dehydrogenase, results in higher ethanol yield but lower productivity. Instead, the hybrid model shows the need to overexpress this oxidative PP pathway to increase ethanol productivity. The calculations show an increase in productivity though there is a small drop in the yield.

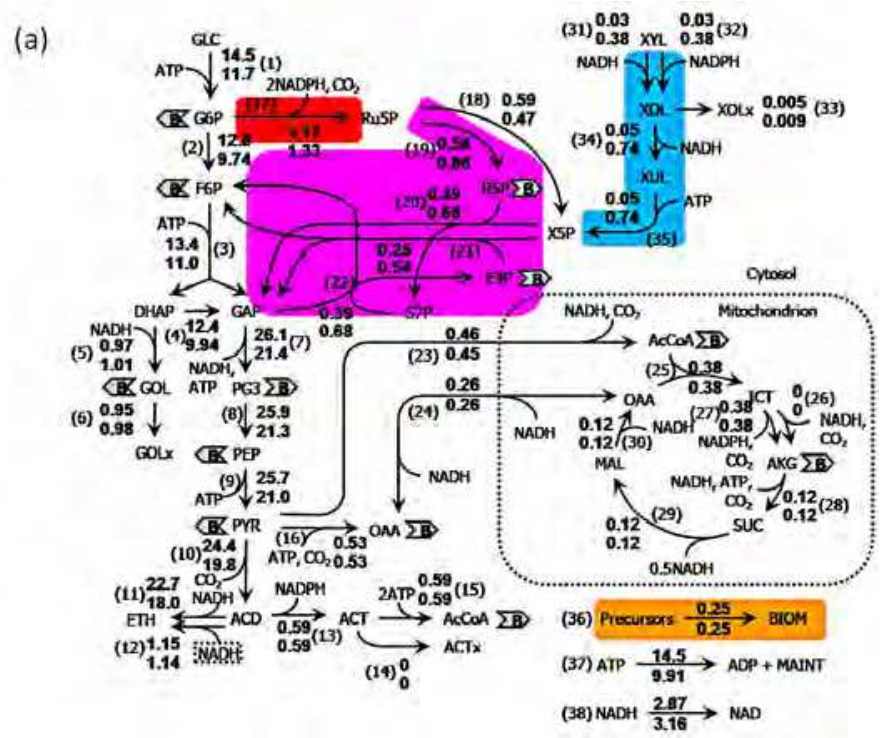

(b)

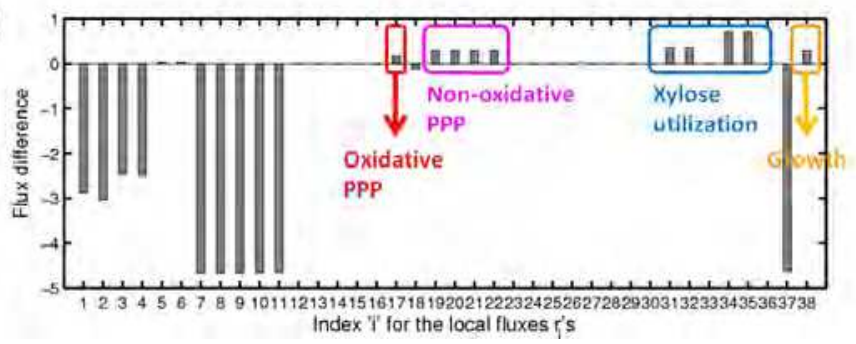

Fig. 3.3. Comparison between before and after amplifying the flux of the target mode (EM6). (a) Flux distributions within the network. The upper and lower numerical values along arrow denote the magnitude of fluxes before $(\mathbf{r})$ and after $\left(\mathbf{r}^{\prime}\right)$ the genetic change. The unit of flux is $\mathrm{mmol} / \mathrm{gDW} / \mathrm{h}$. (b) Difference between $\mathbf{r}^{\prime}$ and $\mathbf{r}$.

\section{Reactor-level approaches}

In this section, we discuss reactor-level strategies towards the enhanced ethanol productivity in two ways. First, we seek optimal ratios of glucose and xylose in batch and continuous cultures to maximize bioethanol productivity. Second, various configurations combining batch, fed-batch and continuous reactors are considered. Their maximum achievable productivities are assessed using the model for the original recombinant strain $S$. cerevisiae 1400 (pLNH33) (i.e., with no amplification of EM6 flux).

The ethanol productivity in a batch and continuous reactor is computed as follows: 


$$
P_{E T H} \equiv \begin{cases}{\left[x_{E T H}\left(t_{f}\right)-x_{E T H}(0)\right] /\left(t_{f}+t_{s}\right)} & \text { (batch) } \\ {\left[x_{E T H}(t)-x_{E T H, I N}\right] D} & \text { (continuous) }\end{cases}
$$

where $x_{E T H, I N}$ is the ethanol concentration in the feed (which is zero in our case), $t_{s}$ is the extra time taken for harvesting and preparation for the next batch. The normal range of $t_{s}$ is from 3 to 10 hours (Shuler \& Kargi, 2002) and we set it to 6 hours.

\subsection{Effect of sugar composition}

We examine the effect of increasing the portion of xylose in the culture medium on ethanol productivity (Fig. 4.1). The total conversion of mixed sugars is set to 0.99 as before. Additional xylose is assumed obtainable by collecting an unconverted sugar from fermentation systems using wild-type yeast which converts glucose only.
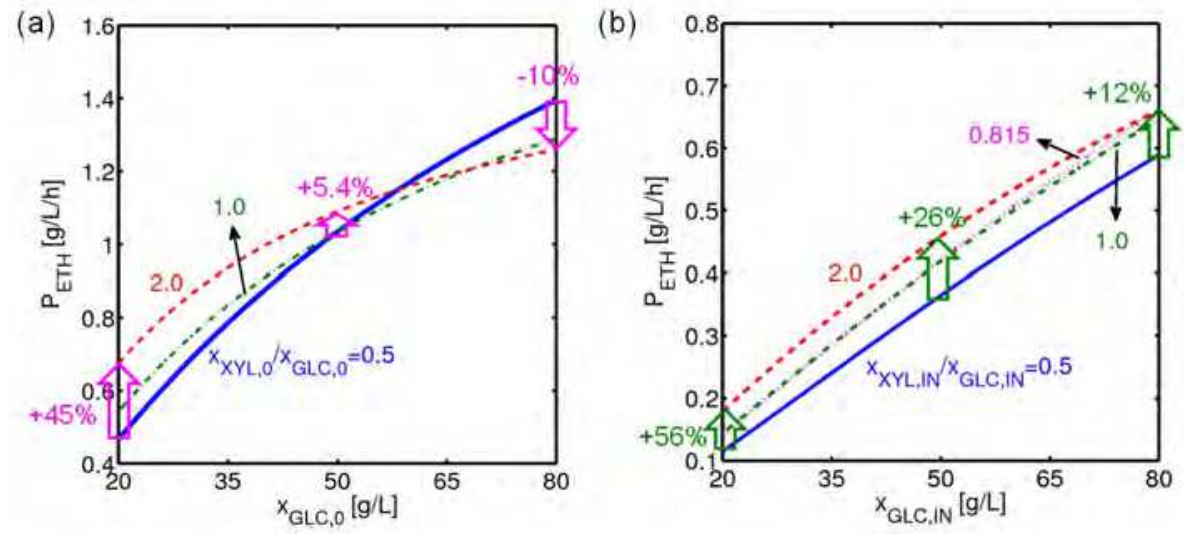

Fig. 4.1. Productivities with different initial sugar concentration in (a) batch and (b) continuous reactors. Adapted from Song and Ramkrishna (2010).

First, the change of ethanol productivity with initial glucose concentration in a batch reactor is given in Fig. 4.1 (a). Ethanol productivity may or may not increase with the ratio of xylose to glucose concentration depending on initial glucose concentrations. If, for example, the upper limit of $x_{X Y L, 0} / x_{G L C, 0}$ is 1.0, xylose addition results in increase (or decrease) of productivity when $x_{G L C, 0}$ is below (or above) about $50 \mathrm{~g} / \mathrm{L}$. If the ratio of initial sugar concentration is allowed to vary up to 2.0 , such threshold is extended to $x_{G L C, 0}=58 \mathrm{~g} / \mathrm{L}$. Higher improvement of ethanol productivity is expected for lower initial concentrations of glucose (e.g., $45 \%$ up at $x_{G L C, 0}=20 \mathrm{~g} / \mathrm{L}$, but $5.4 \%$ up at $x_{G L C, 0}=50 \mathrm{~g} / \mathrm{L}$ ). Optimal operating conditions correspond to segments of curves above other ones. In Fig. 4.1(a), for example, optimal operating conditions imply that $\mathrm{x}_{\mathrm{XYL}, 0} / \mathrm{x}_{\mathrm{GLC}, 0}=2$ when $20 \leq \mathrm{x}_{\mathrm{GLC}, 0} \leq 58$, and $\mathrm{x}_{\mathrm{XYL}, 0} / \mathrm{x}_{\mathrm{GLC}, 0}=0.5$ when $58 \leq \mathrm{x}_{\mathrm{GLC}, 0} \leq 80$.

Next, operating curves in a continuous reactor are presented in Fig. 4.1(b). It is shown that, unlike the batch case, it is always recommendable to increase xylose level in the feed to increase the ethanol productivity. The best productivity is obtained when $x_{X Y L, I N} / x_{G L C, I N}=$ 2.0 , which increases the productivity by $56 \%, 26 \%$, and $12 \%$ at $x_{G L C, I N}=20,50$, and $80 \mathrm{~g} / \mathrm{L}$, respectively. 


\subsection{Comparison of batch and continuous reactors}

Ethanol productivity curves at standard conditions in batch and continuous systems are collected together in Fig. 4.2 for clear comparison. In general, the productivity of growthassociated products in a chemostat is far higher than in a batch reactor. This is not the case with ethanol production because it is suppressed by growth (Shuler \& Kargi, 2002). The ethanol productivity from mixed sugars in batch culture is about two to three times higher than in continuous culture (Fig. 4.2(a)). Meanwhile, the foregoing considerations show that chemostats outperform batch fermenters in ethanol production from glucose alone as cells grow relatively fast (Fig. 4.2(b)). Choice of preculture medium affects ethanol productivity of batch fermentation and its effect is more clearly shown for mixed sugars (Fig. 4.2(a)) than a single substrate (Fig. 4.2(b)).
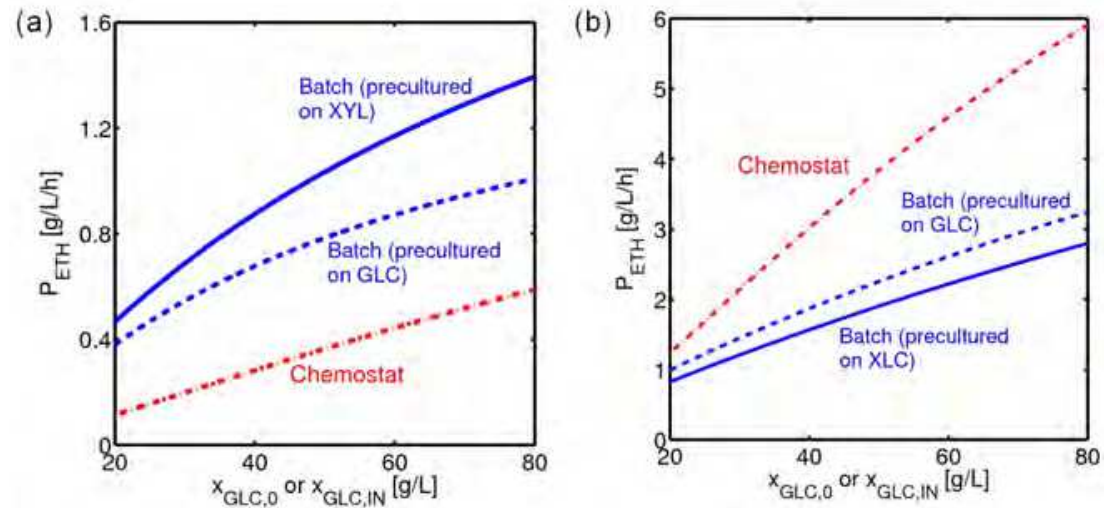

Fig. 4.2. Performance comparison between batch and continuous systems: (a) fermentation of mixed sugars, (b) fermentation of glucose only. Adapted from Song and Ramkrishna (2010).

\subsection{Synergistic integration of different type of reactors}

In the preceding section, the possibility of improving the productivity in batch reactors was examined by increasing the initial concentration of xylose. Elevation of xylose concentration has both positive and negative effects, i.e., it facilitates simultaneous consumption initially, but prolongs the fermentation time after glucose consumption. Overall, this trade-off resulted in the increase of ethanol productivity only at low sugar concentrations. It was further shown that continuous operation produces significantly more ethanol than batch when only glucose is consumed, but less when mixed sugars are consumed. These findings suggest the investigation of new reactor configurations which may outperform conventional batch fermentation.

We consider the following five configurations (denoted by $\mathrm{C} 1$ to $\mathrm{C} 5$ ), each of which combines two different reactor operations (O1 and O2) (Table 4.1). C1 represents a conventional batch operation where mixed sugars are fermented to ethanol by recombinant S. cerevisiae. The same is repeated at every batch (i.e., $\mathrm{O} 1$ is identical to $\mathrm{O} 2$ ). In $\mathrm{C} 2, \mathrm{O} 1$ is a batch reactor for the growth of the "wild-type" S. cerevisiae which can ferment glucose alone. Leftover sugars in $\mathrm{O} 1$ are then fed to $\mathrm{O} 2$ (i.e., fed-batch operation) where mixed sugars are fermented using the recombinant strain. C3 is the same as C2 except that a chemostat is used 


\begin{tabular}{cllllll}
\hline \multirow{2}{*}{ Config. } & \multicolumn{3}{c}{ Operation 1 (O1) } & \multicolumn{3}{c}{ Operation 2 (O2) } \\
\cline { 2 - 7 } & Reactor & Strain & Sugar & Reactor & Strain & Sugar \\
\hline C1 & Batch & GM & GLC, XYL & Batch. & GM & GLC, XYL \\
C2 & Batch & WT & GLC & Fed-batch & GM & GLC, XYL \\
C3 & Cont. & WT & GLC & Fed-batch & GM & GLC, XYL \\
C4 & Batch & WT & GLC & Fed-batch & GM & GLC, XYL \\
C5 & Cont. & WT & GLC & Fed-batc & GM & GLC, XYL \\
\hline
\end{tabular}

Table 4.1. Reactor configurations integrating two different types of reactors. Acronyms: C1 to $\mathrm{C} 5=$ reactor configurations 1 to $5, \mathrm{GM}=$ genetically modified strain, $\mathrm{WT}=$ wild-type strain. GLC $=$ glucose, $\mathrm{XYL}=$ xylose. Redrawn from Song et al. (2011).

for $\mathrm{O} 1$. $\mathrm{C} 4$ and $\mathrm{C} 5$ are respective counterparts of $\mathrm{C} 2$ and $\mathrm{C} 3$, and these two groups are differentiated only by the xylose feeding policy in O2. That is, in C2 and C3, all leftover sugars in $\mathrm{O} 1$ are fed into $\mathrm{O} 2$ at its start-up (which implies that $\mathrm{O} 2$ is a batch system with elevated initial concentration of xylose). In C4 and C5, on the other hand, the xylose feeding rate is optimized such that the ethanol productivity in $\mathrm{O} 2$ is maximized.

We introduced a continuous reactor in $\mathrm{C} 3$ and $\mathrm{C} 5$ in the above. Chemostats have been preferred less than batch reactors in practice. One of the primary reasons for this is the genetic instability of fermenting organisms as continuous operation will impose strong selective pressure of fast growing cells instead of efficient ethanol producers. This will pose a serious problem for recombinant yeast strains, but may not for the wild-type. Thus, we consider C3 and C5 also as practically meaningful configurations.

In Table 4.2, an overall comparison is made for C1 to C5 at three different sugar concentrations with respect to the actual productivity and its relative change (in comparison to $\mathrm{C} 1$ ), respectively. From the comparison of the $\mathrm{C} 2-\mathrm{C} 3$ group and the $\mathrm{C} 4-\mathrm{C} 5$ group, it is clear that the effect of optimizing the feed rate is most significant at high sugar concentration, and appreciable at medium, but least at low. Strangely, at $[G L C] /[X Y L]=20 / 10$, the productivities of C4 and C5 with optimal feeding policies are lower than those of $\mathrm{C} 2$ and $\mathrm{C} 3$, respectively, where all extra sugars are dumped into reactors at their start-up without optimization. This is because the initial feeding of C2 and C3 is closer to the "true" optimal than the feed profiles of C4 and C5 obtained from direct methods involving control profile discretization (Song et al., 2011). Other than this exception, C5 exhibits the highest productivity among all other configurations. In

\begin{tabular}{cccc}
\hline \multicolumn{4}{c}{ Productivity (increase or decrease in comparison to C1) } \\
\hline & {$[\mathrm{GLC}] /[\mathrm{XYL}]=20 / 10$} & $70 / 35$ & $120 / 60$ \\
\hline $\mathrm{C} 1$ & 0.43 & 1.04 & 1.30 \\
$\mathrm{C} 2$ & $0.51(19 \%)$ & $1.06(2 \%)$ & $1.22(-6 \%)$ \\
C3 & $0.66(52 \%)$ & $1.29(23 \%)$ & $1.40(8 \%)$ \\
C4 & $0.51(18 \%)$ & $1.13(9 \%)$ & $1.41(9 \%)$ \\
C5 & $0.64(48 \%)$ & $1.34(29 \%)$ & $1.60(23 \%)$ \\
\hline
\end{tabular}

Table 4.2. Total bioethanol productivities of $\mathrm{C} 1$ to $\mathrm{C} 5$ and relative increase (or decrease) of productivities of $\mathrm{C} 2$ to $\mathrm{C} 4$ in comparison to $\mathrm{C} 1$. The total conversion of mixed sugars in all configurations is fixed to 0.95 . Redrawn from Song et al. (2011). 
comparison to $\mathrm{C} 1, \mathrm{C} 5$ achieves a substantial increase of the bioethanol productivity, i.e., by 48,29 and $23 \%$ when [GLC]/[XYL] = 20/10, 70/35, and 120/60, respectively. [GLC]/[XYL] denotes the mass concentration ratio of glucose and xylose.

\section{Conclusion}

Various possibilities of increasing the productivity of lignocellosic bioethanol at the fermentation step have been discussed, including metabolic pathway modification of fermenting organisms, optimization of reactor operating conditions, and synergistic combination of different types of reactors. Mathematical models play a key role in establishing rational strategies at such diverse levels. The success of the proposed methods, of course, depends on the reliability of the employed mode. We have demonstrated that the cybernetic models are uniquely effective for the in silico analysis of fermentation systems in view of their capacity to address productivity.

In regard to strain modification, it is emphasized that increasing the productivity rather than the yield is a more suitable goal as the former is directly related to economic competiveness. Note that emphasis on productivity is not at undue expense of yield since any pronounced drop on yield would also lead to a drop in productivity. On the other hand, sole stress on yield at the expense of productivity (due to a possible drop in growth rate) is not conducive to economics. Therefore, in the course of metabolic engineering undergoing several rounds of analysis and synthesis of strains, the productivity issue must be considered from the very outset. While the HCM framework based on a reduced subset of EMs can be useful in developing basic guidelines for flux redistribution of fermenting organisms, reasonable interpretation should be made under the possible loss of modes with significance for strain improvement. For metabolic engineering application, more sophisticated frameworks such as Lumped HCM (L-HCM) (Song \& Ramkrishna, 2010; 2011) or Young's model (Young et al., 2008) represent promising methodologies in the future.

It is also shown that the productivity of lignocellulosic bioethanol can significantly be enhanced by synergistic combination of continuous and fed-batch reactors and optimizing their operating conditions. While experimental verification should follow, our model-based study provides solid proof-of-concept support for the success of the proposed methods.

\section{Acknowledgment}

The authors acknowledge a special grant from the Dean's Research Office at Purdue University for support.

\section{References}

Bailey, J. E. (1998). Mathematical modeling and analysis in biochemical engineering: Past accomplishments and future opportunities. Biotechnology Progress, Vol. 14, No. 1, pp. 8-20, ISSN 8756-7938

Bentley, W. E.; Mirjalili, N.; Andersen, D. C.; Davis, R. H. \& Kompala, D. S. (1990). PlasmidEncoded Protein - the Principal Factor in the Metabolic Burden Associated with Recombinant Bacteria. Biotechnology and Bioengineering, Vol. 35, No. 7, pp. 668-681, ISSN 0006-3592 
Binod, P.; Sindhu, R.; Singhania, R. R.; Vikram, S.; Devi, L.; Nagalakshmi, S.; Kurien, N.; Sukumaran, R. K. \& Pandey, A. (2010). Bioethanol production from rice straw: An overview. Bioresource Technology, Vol. 101, No. 13, pp. 4767-4774, ISSN 09608524

Cardona C. A.; Quintero J. A.; Paz I. C. (2010). Production of bioethanol from sugarcane bagasse: Status and perspectives. Bioresource Technology, Vol. 101, No. 13, pp. 47544766, ISSN 0960-8524

Chu, B. C. H. \& Lee, H. (2007). Genetic improvement of Saccharomyces cerevisiae for xylose fermentation. Biotechnology Advances, Vol. 25, No. 5, pp. 425-441, ISSN 0734-9750

Glick, B. R. (1995). Metabolic Load and Heterologous Gene-Expression. Biotechnology Advances, Vol. 13, No. 2, pp. 247-261, ISSN 0734-9750

Hahn-Hagerdal, B.; Karhumaa, K.; Fonseca, C.; Spencer-Martins, I. \& Gorwa-Grauslund, M. F. (2007). Towards industrial pentose-fermenting yeast strains. Applied Microbiology and Biotechnology, Vol. 74, No. 5, pp. 937-953, ISSN 0175-7598

Jeppsson, M.; Johansson, B.; Hahn-Hagerdal, B. \& Gorwa-Grauslund, M. F. (2002). Reduced oxidative pentose phosphate pathway flux in recombinant xyloseutilizing Saccharomyces cerevisiae strains improves the ethanol yield from xylose. Applied and Environmental Microbiology, Vol. 68, No. 4, pp. 1604-1609, ISSN 0099-2240

Johansson, B. \& Hahn-Hagerdal, B. (2002). Overproduction of pentose phosphate pathway enzymes using a new CRE-loxP expression vector for repeated genomic integration in Saccharomyces cerevisiae. Yeast, Vol. 19, No. 3, pp. 225-231, ISSN 0749-503X

Kadam, K. L. \& McMillan, J. D. (2003). Availability of corn stover as a sustainable feedstock for bioethanol production. Bioresource Technology, Vol. 88, No. 1, pp. 17-25, ISSN 0960-8524

Keshwani, D. R. \& Cheng, J. J. (2009). Switchgrass for bioethanol and other value-added applications: A review. Bioresource Technology, Vol. 100, No. 4, pp. 1515-1523, ISSN 0960-8524

Kim, J. I.; Varner, J. D. \& Ramkrishna, D. (2008). A Hybrid Model of Anaerobic E. coli GJT001: Combination of Elementary Flux Modes and Cybernetic Variables. Biotechnology Progress, Vol. 24, No. 5, pp. 993-1006, ISSN 8756-7938

Klamt, S. \& Stelling, J. (2002). Combinatorial complexity of pathway analysis in metabolic networks. Molecular Biology Reports, Vol. 29, No. 1-2, pp. 233-236, ISSN 0301-4851

Koebmann, B. J.; Westerhoff, H. V.; Snoep, J. L.; Nilsson, D. \& Jensen, P. R. (2002). The glycolytic flux in Escherichia coli is controlled by the demand for ATP. Journal of Bacteriology, Vol. 184, No. 14, pp. 3909-3916, ISSN 0021-9193

Kompala, D. S.; Ramkrishna, D.; Jansen, N. B. \& Tsao, G. T. (1986). Investigation of Bacterial-Growth on Mixed Substrates - Experimental Evaluation of Cybernetic Models. Biotechnology and Bioengineering, Vol. 28, No. 7, pp. 1044-1055, ISSN 00063592

Krishnan, M. S.; Xia, Y.; Ho, N. W. Y. \& Tsao, G. T. (1997). Fuel ethanol production from lignocellulosic sugars - Studies using a genetically engineered Saccharomyces yeast. Fuels and Chemicals from Biomass, Vol. 666, pp. 74-92, ISSN 0097-6156

Lange, J. P. (2007). Lignocellulose conversion: an introduction to chemistry, process and economics. Biofuels Bioproducts \& Biorefining-Biofpr, Vol. 1, No. 1, pp. 39-48, ISSN 1932-104X 
Lee, S. B.; Seressiotis, A. \& Bailey, J. E. (1985). A Kinetic-Model for Product Formation in Unstable Recombinant Populations. Biotechnology and Bioengineering, Vol. 27, No. 12, pp. 1699-1709, ISSN 0006-3592

Maertens, J. \& Vanrolleghem, P. A. (2010). Modeling with a View to Target Identification in Metabolic Engineering: A Critical Evaluation of the Available Tools. Biotechnology Progress, Vol. 26, No. 2, pp. 313-331, ISSN 8756-7938

Ramkrishna, D. (1983). A Cybernetic Perspective of Microbial-Growth. Acs Symposium Series, Vol. 207, pp. 161-178, ISSN 0097-6156

Ricci, J. C. D. \& Hernandez, M. E. (2000). Plasmid effects on Escherichia coli metabolism. Critical Reviews in Biotechnology, Vol. 20, No. 2, pp. 79-108, ISSN 0738-8551

Satyagal, V. N. \& Agrawal, P. (1989). A Generalized-Model of Plasmid Replication. Biotechnology and Bioengineering, Vol. 33, No. 9, pp. 1135-1144, ISSN 0006-3592

Schaaff, I.; Heinisch, J. \& Zimmermann, F. K. (1989). Overproduction of Glycolytic-Enzymes in Yeast. Yeast, Vol. 5, No. 4, pp. 285-290, ISSN 0749-503X

Schuster, S.; Fell, D. A. \& Dandekar, T. (2000). A general definition of metabolic pathways useful for systematic organization and analysis of complex metabolic networks. Nature Biotechnology, Vol. 18, No. 3, pp. 326-332, ISSN 1087-0156

Shuler, M. L. \& Kargi, F. (2002). Bioprocess Engineering. Basic Concepts. Upper Saddle River: Prentice-Hall, Inc., ISBN 978-0130819086.

Song, H.-S. \& Ramkrishna, D. (2009). Reduction of a Set of Elementary Modes Using Yield Analysis. Biotechnology and Bioengineering, Vol. 102, No. 2, pp. 554-568, ISSN 00063592

Song, H.-S. \& Ramkrishna, D. (2010). Prediction of Metabolic Function From Limited Data: Lumped Hybrid Cybernetic Modeling (L-HCM). Biotechnology and Bioengineering, Vol. 106, No. 2, pp. 271-284, ISSN 0006-3592

Song, H.-S. \& Ramkrishna, D. (2011). Cybernetic Models Based on Lumped Elementary Modes Accurately Predict Strain-Specific Metabolic Function. Biotechnology and Bioengineering, Vol. 108, No. 1, pp. 127-140, ISSN 0006-3592

Song, H.-S.; Kim, S. J. \& Ramkrishna, D. (2011). Synergistic Optimal Integration of Continuous and Fed-Batch Reactors for Enhanced Productivity of Lignocellulosic Bioethanol. Industrial \& Engineering Chemistry Research, DOI: 10.1021/ie200879s, ISSN: 0888-5885

Song, H.-S.; Morgan, J. A. \& Ramkrishna, D. (2009). Systematic Development of Hybrid Cybernetic Models: Application to Recombinant Yeast Co-Consuming Glucose and Xylose. Biotechnology and Bioengineering, Vol. 103, No. 5, pp. 984-1002, ISSN 00063592

Talebnia, F.; Karakashev, D. \& Angelidaki, I. (2010). Production of bioethanol from wheat straw: An overview on pretreatment, hydrolysis and fermentation. Bioresource Technology, Vol. 101, No. 13, pp. 4744-4753, ISSN 0960-8524

von Kamp, A. \& Schuster, S. (2006). Metatool 5.0: fast and flexible elementary modes analysis. Bioinformatics, Vol. 22, No. 15, pp. 1930-1931, ISSN 1367-4803

Wingren, A.; Galbe, M. \& Zacchi, G. (2003). Techno-economic evaluation of producing ethanol from softwood: Comparison of SSF and SHF and identification of bottlenecks. Biotechnology Progress, Vol. 19, No. 4, pp. 1109-1117, ISSN 8756-7938

Young, J. D. \& Ramkrishna, D. (2007). On the matching and proportional laws of cybernetic models. Biotechnology Progress, Vol. 23, No. 1, pp. 83-99, ISSN 8756-7938 
Young, J. D.; Henne, K. L.; Morgan, J. A.; Konopka, A. E. \& Ramkrishna, D. (2008). Integrating cybernetic modeling with pathway analysis provides a dynamic, systems-level description of metabolic control. Biotechnology and Bioengineering, Vol. 100, No. 3, pp. 542-559, ISSN 0006-3592 


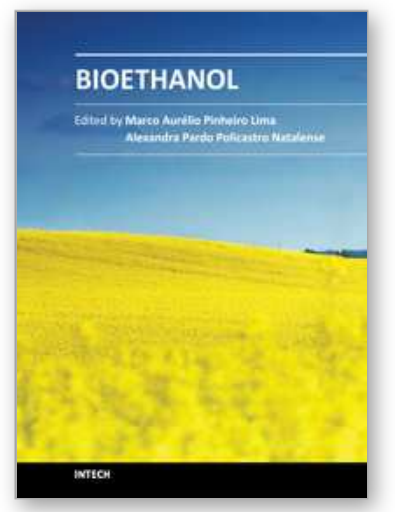

\author{
Bioethanol \\ Edited by Prof. Marco Aurelio Pinheiro Lima
}

ISBN 978-953-51-0008-9

Hard cover, 290 pages

Publisher InTech

Published online 01, February, 2012

Published in print edition February, 2012

Recent studies have shown strong evidence of human activity impact on the climate of the planet. Higher temperatures and intensification of extreme weather events such as hurricanes are among the consequences. This scenario opens up several possibilities for what is now called "green" or low carbon economy. We are talking about creating new businesses and industries geared to develop products and services with low consumption of natural resources and reduced greenhouse gases emission. Within this category of business, biofuels is a highlight and the central theme of this book. The first section presents some research results for first generation ethanol production from starch and sugar raw materials. Chapters in the second section present results on some efforts around the world to develop an efficient technology for producing secondgeneration ethanol from different types of lignocellulosic materials. While these production technologies are being developed, different uses for ethanol could also be studied. The chapter in the third section points to the use of hydrogen in fuel cells, where this hydrogen could be produced from ethanol.

\title{
How to reference
}

In order to correctly reference this scholarly work, feel free to copy and paste the following:

Hyun-Seob Song, John A. Morgan and Doraiswami Ramkrishna (2012). Towards Increasing the Productivity of Lignocellulosic Bioethanol: Rational Strategies Fueled by Modeling, Bioethanol, Prof. Marco Aurelio Pinheiro Lima (Ed.), ISBN: 978-953-51-0008-9, InTech, Available from:

http://www.intechopen.com/books/bioethanol/towards-increasing-the-productivity-of-lignocellulosic-bioethanolrational-strategies-fueled-by-mode

\section{INTECH}

open science | open minds

\section{InTech Europe}

University Campus STeP Ri

Slavka Krautzeka 83/A

51000 Rijeka, Croatia

Phone: +385 (51) 770447

Fax: +385 (51) 686166

www.intechopen.com

\section{InTech China}

Unit 405, Office Block, Hotel Equatorial Shanghai

No.65, Yan An Road (West), Shanghai, 200040, China 中国上海市延安西路65号上海国际贵都大饭店办公楼405单元

Phone: +86-21-62489820

Fax: $+86-21-62489821$ 
(C) 2012 The Author(s). Licensee IntechOpen. This is an open access article distributed under the terms of the Creative Commons Attribution 3.0 License, which permits unrestricted use, distribution, and reproduction in any medium, provided the original work is properly cited. 